\title{
Consumo e Digestibilidades Aparentes Totais e Parciais de Rações Contendo Diferentes Níveis de Concentrado, em Novilhos F1 Limousin x Nelore ${ }^{1}$
}

\section{Rodrigo Carvalho Cardoso², Sebastião de Campos Valadares Filho ${ }^{3}$, José Fernando Coelho da Silva ${ }^{4}$, Mário Fonseca Paulino ${ }^{3}$, Rilene Ferreira Diniz Valadares ${ }^{3}$, Paulo Roberto Cecon ${ }^{3}$, Marco Antônio Lana Costa ${ }^{5}$, Rodrigo Vidal de Oliveira 6}

RESUMO - O objetivo deste trabalho foi avaliar os efeitos de cinco níveis de concentrados $(25,0 ; 37,5 ; 50,0 ; 62,5$; e 75,0\%) sobre os consumos e as digestibilidades aparentes totais e parciais da matéria seca (MS), matéria orgânica (MO), proteína bruta (PB), do extrato etéreo (EE), dos carboidratos totais (CHO) e da fibra em detergente neutro (FDN). Cinco novilhos $\mathrm{F}_{1}$ Limousin x Nelore, não-castrados, com peso médio inicial de $279 \mathrm{~kg}$, fistulados no rúmen, abomaso e íleo, foram usados em um delineamento quadrado latino $5 \times 5$, com cinco tratamentos, cinco períodos experimentais e cinco animais. Cada período teve duração de 14 dias - 10 dias para adaptação dos animais à ração e quatro dias para coleta de fezes e de digestas de abomaso e íleo. Utilizou-se o óxido crômico em duas doses de $10 \mathrm{~g} /$ dia, como indicador, para medir os fluxos de nutrientes no trato digestivo. Os consumos de EE e NDT aumentaram e o de FDN diminuiu linearmente com o incremento dos níveis de concentrados das rações. O aumento de níveis de concentrado na MS da ração resultou em acréscimos lineares nas digestilidades totais de MS, MO, PB, EE e CHO. A digestibilidade aparente total de FDN e as digestões aparentes ruminais de MS, MO, PB, CHO e FDN não foram influenciadas pelos níveis de concentrado nas rações, observando-se médias de 45,91; 54,45; 64,67; -9,92; 79,29; e 95,90\%, respectivamente. Conclui-se que o aumento dos níveis de concentrado nas rações não alterou os locais de digestão dos nutrientes.

Palavras-chave: bovinos, concentrado, consumo, digestibilidade

\section{Intake and Total and Partial Apparent Digestibilities of Diets with Different Concentrate Levels, in F1 Limousin x Nellore Bulls}

\begin{abstract}
The objective of this work was to evaluate the effects of five dietary concentrate levels (25.0, 37.5, 50.0, 62.5, and $75.0 \%$ ) on intake and the total and partial apparent digestibilities of dry matter (DM), organic matter (OM), crude protein (CP), ether extract (EE), total carbohydrates (CHO) and neutral detergent fiber (NDF). Five rumen, abomasum and ileum fistulated F1 Limousin $\mathrm{x}$ Nellore bulls, with average initial weight of $279 \mathrm{~kg}$ were used, in a 5 x 5 Latin square design, with five treatments, five experimental periods and five animals. Each experimental period lasted 14 days - 10 days for animals adaptation to the diet and four days for feces, and abomasum and ileum digesta collection. Chromium oxide was used as indicator, in two doses of $10 \mathrm{~g} /$ day, to measure nutrient flows in the digestive tract. The ether extract and TDN intakes increased and of the NDF linearly decreased with the increase of dietary concentrate levels. The increment of concentrate levels in DM linearly increased the apparent total digestibilities of the DM, OM, CP, and CHO. The apparent total NDF digestibility and the apparent ruminal digestibilities of DM, OM, CP, CHO and FDN were not influenced by the dietary concentrate levels, with means of $45.91,54.45,64.67,-9.92,79.29$, and $95.90 \%$, respectively. The increase of dietary concentrate levels did not affect the local of nutrients digestion.
\end{abstract}

Key Words: bovine, concentrate, intake, digestibility

\section{Introdução}

O principal objetivo dos nutricionistas é ajustar a quantidade e a qualidade da ração baseando-se nas exigências dos animais. A ingestão voluntária é determinante para o balanceamento de rações e para o estabelecimento de estratégias de alimentação que permitam maior desempenho de bovinos (VAN SOEST, 1994;
NATIONAL RESEARCH COUNCIL - NRC, 1996).

Existem vários fatores envolvidos no controle da ingestão de alimentos em bovinos: MERTENS (1994) e SNIFFEN et al. (1993) os dividem em três mecanismos: o psicogênico, que envolve a resposta animal a fatores inibidores ou estimuladores relacionados ao alimento e ao ambiente; o fisiológico, no qual o controle é feito pelo balanço nutricional da ração,

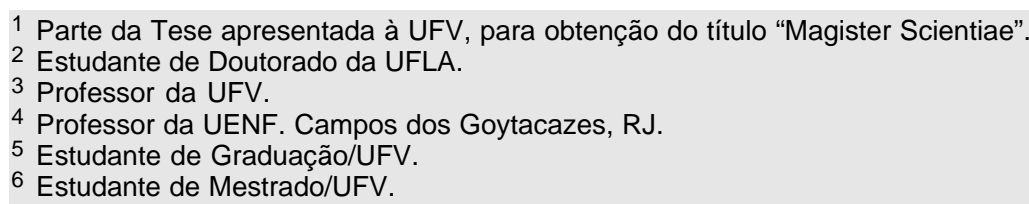


relacionado à manutenção do equilíbrio energético; e o físico, associado à capacidade de distensão do rúmen e ao teor de FDN da ração.

A digestibilidade da forragem determina o desaparecimento de nutrientes no rúmen. Em rações com taxas de digestão dos nutrientes acima de $66 \%$ de digestibilidade aparente total, há menor resíduo ruminal e rápida renovação de material no rúmen; forragens de melhor qualidade atingem rapidamente os pontos finais de digestão, minimizando a limitação de consumo pelo "enchimento" (PATERSON et al., 1994).

Quando o animal consome forragens de baixa qualidade, além do limite físico do rúmen, o consumo pode ser limitado pela deficiência em proteína da ração (DOVE, 1996). Em rações desbalanceadas, com baixa disponibilidade de compostos nitrogenados (N) e ricas em FDN, suprimento de proteína degradada no rúmen (PDR) é limitante para o crescimento microbiano, a digestão da parede celular fica comprometida e a ingestão de alimentos é reduzida.

Os pontos críticos para se estimar consumo são as limitações relativas entre os animais, o alimento fornecido e as condições de alimentação. Basicamente, em rações formuladas com elevado teor de fibra, ou baixa densidade energética em relação às exigências, o consumo será limitado pelo efeito de "enchimento" do rúmen-retículo. Se a densidade energética for elevada, ou a concentração de fibra for baixa em relação às exigências, a ingestão passa ser limitada pela demanda fisiológica de energia. A correlação existente entre ingestão de FDN, ruminação e salivação é indispensável para manter a atividade ruminal e o consumo de alimentos (VAN SOEST e MERTENS, 1984; MERTENS, 1988; e MERTENS, 1994).

O consumo e a digestibilidade de nutrientes podem estar correlacionados entre si, dependendo da qualidade da ração. Para rações de alta digestibilidade (acima de 66\%), ricas em concentrados (acima de $75 \%$ ) e com baixo teor de FDN (abaixo de $25 \%$ ), o consumo será menor quanto mais digestivo for o alimento e, em rações de baixa qualidade (acima de $75 \%$ de FDN), o consumo será maior quanto melhor for a digestibilidade do alimento (VAN SOEST, 1994; MERTENS, 1994).

Rações variando a relação volumoso para concentrado (80:20, 60:40 e 40:60), utilizando feno de capim-coastcross, BERCHIELLI (1994) verificou que os consumos expressos em $\mathrm{g} / \mathrm{kg}^{0,75}$ foram superiores nas rações com 40 e $60 \%$ de concentrado, atribuindo este efeito à capacidade de "enchimento" do rúmen, $80 \%$ de volumoso limitou o consumo.

TIBO et al. (1997), ao aumentarem os níveis de concentrado das rações, observaram redução linear no consumo de FDN, expresso em $\mathrm{kg} / \mathrm{dia}$ e \%PV. Para os consumos de MS e MO, encontraram comportamento quadrático, com redução nos consumos desses nutrientes, expresso em $\mathrm{g} / \mathrm{kg}^{0,75}$, a partir de níveis estimados de concentrado de 70,58\%. Os animais consumiram alimentos para manter constante o nível de ingestão de energia, e ao melhorar a digestibilidade da ração adicionando mais concentrado, o consumo de MS foi limitado pelo efeito fisiológico.

A quantidade de FDN na dieta não está definida e pode variar em função do nível de produção animal e do tipo de forragem utilizada. É desejável que o teor de FDN da ração exceda 25\% da MS (MERTENS, 1992) e 70 a $75 \%$ dessa FDN seja fornecida na forma de volumosos para manter as condições ideais dentro do rúmen ( $\mathrm{pH}$, proporção de ácidos graxos voláteis, população microbiana) e não prejudicar a digestibilidade.

Trabalhando com feno de capim-gordura (Melinis menutiflora), ANDRADE (1992) observou maior digestão ruminal da MS $(62,3 \%)$ para $20 \%$ de concentrado na ração. Observou que a ração com $60 \%$ de concentrado foi melhor digerida no intestino delgado (ID), contribuindo para aumentar o suprimento de glicose para o ruminante.

DUTRA et al. (1997), alimentando mestiços holandês-zebu com rações contendo 57,2 e $38,7 \%$ de FDN, encontraram efeito do nível de fibra para as digestões aparentes totais de MS e MO, que variaram de 52,23 a $38,71 \%$ e 54,73 a $42,02 \%$, respectivamente. Os coeficientes de digestibilidade ruminal, no ID e IG, foram, em média, de 48,9; 47,0; e 4,2\% para MS e 60,$0 ; 43,0$; e $3,0 \%$ para a MO, respectivamente. Os níveis de FDN não influenciaram as digestibilidades aparentes total e parcial da PB e FDN, exceto no IG para a FDN. As digestibilidades no rúmen e nos intestinos delgado e grosso foram, em média, -29,9; 60,2; e $-4,4$ para a PB e 141,$6 ;-45,7$; e 2,6\% para a FDN.

Este experimento foi conduzido a fim de se avaliarem os efeitos de cinco níveis de concentrados, adicionados ao feno de capim-coastcross, sobre os consumos e as digestibilidades aparente totais e parciais da matéria seca (MS), matéria orgânica (MO), proteína bruta (PB), do extrato etéreo(EE), dos carboidratos totais $(\mathrm{CHO})$ e da fibra em detergente neutro (FDN), utilizando-se cinco novilhos $1 / 2$ Limousin x Nelore. 
1834 Rev. bras. zootec.

\section{Material e Métodos}

Foram utilizados cinco novilhos mestiços F1 Limousin x Nelore, não-castrados, com idade de 18 meses e peso médio inicial de $279 \mathrm{~kg}$, fistulados no rúmen, abomaso e íleo, segundo técnicas descritas por LEÃO e COELHO da SILVA (1980).

Os cinco animais foram distribuídos em quadrado latino $5 \times 5$, contendo cinconíveis de concentrado $(25,0$; 37,$5 ; 50,0 ; 62,5 ;$ e $75,0 \%$ ) e cinco períodos experimentais, e confinados em baias individuais de $3 \times 3 \mathrm{~m}$ de área, bebedouros automáticos, comedouros de concreto e pisos recobertos de borracha. O volumoso utilizado foi o feno de capim-coastcross (Cynodon dactylon) e o concentrado, à base de fubá de milho, farelo de soja, uréia e mistura mineral. A ração total foi balanceada conforme o NRC (1984) com 12\% de PB na matéria seca total. As proporções dos ingredientes nos concentrados são mostradas na Tabela 1. A composição química dos concentrados e do feno encontra-se na Tabela 2 e a composição química das cinco rações, na Tabela 3.

Cada período experimental teve duração de 14 dias - 10 dias para adaptação aos tratamentos e quatro dias para coletas de fezes e digestas de abomaso e íleo. Os animais tiveram seus pesos anotados no início e no final de cada período.

Os animais foram alimentados às 7 h30. A ração total foi fornecida em quantidade suficiente para permitir sobras de $10 \%$, com base no total fornecido. A água foi fornecida à vontade. As sobras foram previamente recolhidas e tiveram seus pesos anotados diariamente para determinação do consumo voluntário. Além das sobras, foram recolhidas e feitas amostras compostas do feno fornecido e das cinco rações concentradas em cada um dos períodos.

Para determinar as digestibilidades, utilizou-se o óxido crômico $\left(\mathrm{Cr}_{2} \mathrm{O}_{3}\right)$ como indicador externo, via fístula ruminal, na quantidade total de $20 \mathrm{~g}$, dividida em duas aplicações diárias, às 8 e às 17 h, durante os últimos sete dias de adaptação à ração e os quatro dias de coleta das digestas de abomaso, íleo e fezes.

As digestas e as amostras de fezes foram coletadas duas vezes ao dia, conforme metodologia descrita por ZINN et al. (1994), respeitando o esquema: dia 1 coleta às $7 \mathrm{~h} 30$ e $13 \mathrm{~h} 30$, dia 2 - coleta às 9 e $15 \mathrm{~h}$, dia 3 - coleta às $10 \mathrm{~h} 30$ e $16 \mathrm{~h} 30$ e dia 4 - coleta às $12 \mathrm{e} 18 \mathrm{~h}$, e armazenadas em congelador.

Ao final de cada período experimental, as amostras foram descongeladas à temperatura ambiente e,

Tabela 1 - Proporção dos ingredientes nos concentrados, expressa na base da matéria natural Table 1 - Proportion of the ingredients in the concentrates, express in as fed basis

\begin{tabular}{|c|c|c|c|c|c|}
\hline \multirow[t]{2}{*}{$\begin{array}{l}\text { Ingrediente } \\
\text { Ingredient }\end{array}$} & \multicolumn{5}{|c|}{$\begin{array}{l}\text { Níveis de concentrado } \\
\text { Levels of concentrate }\end{array}$} \\
\hline & 25,0 & 37,5 & 50,0 & 62,5 & 75,0 \\
\hline Fubá de milho (\%) & 75,70 & 84,11 & 88,35 & 90,81 & 92,42 \\
\hline $\begin{array}{l}\text { Corn starch } \\
\text { Farelo de soja (\%) } \\
\text { Soybean meal }\end{array}$ & 21,14 & 13,25 & 9,25 & 6,93 & 5,42 \\
\hline $\begin{array}{l}\text { Uréia }(\%) \\
\text { Urea }\end{array}$ & 1,51 & 1,22 & 1,07 & 0,99 & 0,91 \\
\hline $\begin{array}{l}\text { Calcário }(\%) \\
\text { Limestone }\end{array}$ & 0,00 & 0,33 & 0,50 & 0,62 & 0,70 \\
\hline $\begin{array}{l}\text { Fosfato bicálcico (\%) } \\
\text { Dicalcium phosphate }\end{array}$ & 0,82 & 0,54 & 0,41 & 0,33 & 0,27 \\
\hline $\begin{array}{l}\text { Cloreto de sódio (\%) } \\
\text { Sodium chlorate }\end{array}$ & 0,77 & 0,51 & 0,39 & 0,30 & 0,26 \\
\hline $\begin{array}{l}\text { Sulfato de zinco } \\
\text { Zinc sulfate }\end{array}$ & 47,20 & 31,42 & 23,55 & 18,86 & 15,69 \\
\hline Sulfato de cobre ${ }^{1}$ & 11,20 & 7,46 & 5,59 & 4,48 & 3,72 \\
\hline $\begin{array}{l}\text { Cupper sulfate } \\
\text { Sulfato de cobalto } \\
\text { Cobalt sulfate }\end{array}$ & 0,14 & 0,10 & 0,07 & 0,06 & 0,05 \\
\hline $\begin{array}{l}\text { Iodato de potássio }{ }^{1} \\
\text { Potassium iodinate }\end{array}$ & 0,30 & 0,20 & 0,15 & 0,12 & 0,10 \\
\hline $\begin{array}{l}\text { Selenito de sódio } \\
\text { Sodium selenite }\end{array}$ & 0,16 & 0,11 & 0,08 & 0,06 & 0,05 \\
\hline
\end{tabular}


em seguida, colocadas em bandejas de alumínio e submetidas à pré-secagem em estufa de ventilação forçada a $65^{\circ} \mathrm{C}$, durante 72 a 96 horas. Posteriormente, foram moídas em moinho com peneira de $1 \mathrm{~mm}$ de porosidade, e uma amostra composta com base no peso seco foi feita para cada animal. Armazenaram-se as amostras compostas em vidros fechados com tampa plástica até análises laboratoriais.

Os teores de matéria seca (MS), matéria orgânica (MO), extrato etéreo (EE), compostos nitrogenados totais (N-total), fibra em detergente neutro (FDN) e cromo foram determinados nas amostras, segundo técnicas descritas por SILVA (1990).

Os carboidratos totais foram calculados pela equação: $100-(\% \mathrm{~PB}+\% \mathrm{EE}+\%$ cinzas). Para o cálculo do consumo de nutrientes digestíveis totais (cNDT), utilizou-se a forma descrita por SNIFFEN et al. (1992), sendo cNDT=(cPB-PBf) $+2,25$ (cEEEEf $)+(\mathrm{cCHO}-\mathrm{CHOf})$, em que $\mathrm{cPB}$, cEE e cCHO significam consumos de $\mathrm{PB}$, EE e $\mathrm{CHO}$, respectivamente, e PBf, EEf e CHOf, teores de PB, EE e CHO nas fezes. Os teores de nutrientes digestíveis totais (NDT) e energia metabolizável (EM) das rações foram calculados assumindo-se que $1 \mathrm{~kg}$ de NDT equivale 4,409 Mcal de ED/kgMS e que a $\mathrm{EM}=0,82 * \mathrm{ED}$.

Apesar de ter sido utilizado o delineamento em quadrado latino no ensaio, para as digestibilidades parciais no intestino delgado e no intestino grosso foi usado delineamento inteiramente casualizado com cinco tratamentos e três repetições, devido à perda de fístulas de íleo em dois animais.
Os dados obtidos foram avaliados mediante análises de variância e regressão, utilizando o programa SAEG - Sistema de Análises Estatísticas e Genéticas (UNIVERSIDADE FEDERAL DE VIÇOSA - UFV, 1995). Os modelos foram escolhidos com base na significância dos coeficientes de regressão, utilizando o teste de "t", a 5\% de probabilidade.

\section{Resultados e Discussão}

Os resultados de consumos médios diários de MS, MO, PB, EE, CHO, FDN e NDT, em kg/dia, os consumos de MS, FDN e NDT, em \%PV e g/kg0,75 e respectivas regressões, coeficientes de variação e determinação, encontram-se na Tabela 4.

Ao se elevarem os níveis de concentrados nas rações, não foram observados efeitos nos consumos de MS, em kg/dia, \%PV e g/kg0,75 , 5,14; 1,58; e 66,75, respectivamente, e de MO, 4,94 kg/dia. Resultados similares foram encontrados por HUSSEIN et al. (1995) e CARVALHO et al. (1997a). Todavia, LADEIRA (1998) e DIAS (1999) verificaram aumentos lineares nos consumos de MS e MO, ao trabalharem com níveis de concentrado semelhantes aos deste experimento. Por outro lado, TIBO et al. (1997) observaram comportamento quadrático para o consumo de MS, com respectivos consumos máximos, em \%PV e gMS/kg ${ }^{0,75}$, estimados com $69,92 \mathrm{e}$ $70,58 \%$ de concentrado, respectivamente.

O consumo médio de $1,58 \%$ PV pode ser considerado baixo em relação ao pressuposto pelo NRC (1996), que cita valores próximos de 2,5\% PV para

Tabela 2 - Teores de matéria seca (MS), matéria orgânica (MO), proteína bruta (PB), extrato etéreo $(\mathrm{EE})$, carboidratos totais (CHO) e fibra em detergente neutro (FDN) dos concentrados e do feno de capim-coastcross

Table 2 - Dry matter (DM), organic matter (OM), crude protein $(C P)$, ether extract $(E E)$, total carbohydrates $(\mathrm{CHO})$ and neutral detergent fiber (NDF) contents (\%) of the concentrates and coastcross hay

\begin{tabular}{|c|c|c|c|c|c|c|}
\hline \multirow[t]{2}{*}{$\begin{array}{l}\text { Nutriente } \\
\text { Nutrient }\end{array}$} & \multicolumn{5}{|c|}{$\begin{array}{l}\text { Níveis de concentrado } \\
\text { Levels of concentrate }\end{array}$} & \multirow[t]{2}{*}{$\begin{array}{c}\text { Feno } \\
\text { Hay }\end{array}$} \\
\hline & 25,0 & 37,5 & 50,0 & 62,5 & 75,0 & \\
\hline $\begin{array}{l}\mathrm{MS} \% \\
D M\end{array}$ & 90,96 & 89,12 & 89,75 & 90,77 & 89,95 & 88,07 \\
\hline $\begin{array}{l}\mathrm{MO}^{1} \\
\mathrm{OM}\end{array}$ & 97,05 & 96,85 & 97,06 & 97,45 & 96,97 & 94,96 \\
\hline $\begin{array}{l}\mathrm{PB}^{1} \\
\mathrm{CP}\end{array}$ & 19,82 & 15,58 & 14,42 & 13,48 & 13,85 & 8,53 \\
\hline $\mathrm{EE}^{1}$ & 2,51 & 2,92 & 3,25 & 3,11 & 3,06 & 0,95 \\
\hline $\mathrm{CHO}^{1}$ & 74,72 & 78,35 & 79,39 & 80,86 & 79,95 & 85,48 \\
\hline $\begin{array}{l}\mathrm{FDN}^{1} \\
N D F\end{array}$ & 11,98 & 12,81 & 12,98 & 12,84 & 12,08 & 83,32 \\
\hline
\end{tabular}

\footnotetext{
1 Porcentagem da MS.
}

1 Percentage of DM. 
1836 Rev. bras. zootec.

bovinos de corte. Possivelmente, o baixo consumo observado neste experimento é atribuído ao excesso de manipulação dos animais. GESUALDI JR. (1999), em novilhos F1 Limousin x Nelore, alimentados com níveis de concentrado iguais as deste experimento, verificou comportamento quadrático para os consumos de MS, expressos em $\mathrm{kg} / \mathrm{dia}$, \% PV e g/ $/ \mathrm{kg}^{0,75}$, estimando-se os respectivos valores máximos de $8,04 \mathrm{~kg}$ de MS, $1,99 \% \mathrm{PV}$ e $89,22 \mathrm{gMS} / \mathrm{kg}^{0}, 75$, com os níveis de concentrado nas rações de 41,42; 36,71; e $37,96 \%$, respectivamente.

MERTENS (1994) destacou que a base para expressar consumo não é a mesma para os mecanismos físicos e fisiológicos de controle. Para rações de baixa qualidade, em que ingestãoé limitada pelo "enchimento" do rúmen, é ideal expressá-lo em \%PV, por se encontrar mais relacionado ao tamanho e à capacidade do trato digestivo. Quando o consumo é limitado pela demanda fisiológica de energia, a melhor forma de expressá-lo é com base no peso metabólico.

$\mathrm{O}$ consumo de FDN, expresso em $\mathrm{kg} / \mathrm{dia}$, \%PV e $\mathrm{g} / \mathrm{kg}^{0,75}$, foi reduzido linearmente $(\mathrm{P}<0,01)$ com o incremento dos níveis de concentrado na ração, o que pode ser atribuído à conseqüente redução no teor de FDN na matéria seca total das rações, quando se elevaram os níveis de concentrado na ração
(Tabela 3). No entanto, DUTRA et al. (1997), trabalharam com novilhos mestiços Holandês x Zebu e não observaram diferença no consumo de FDN para rações ricas ou pobres em fibra $(38,7$ e $57,2 \%$ de FDN na MS total). Esses autores encontraram consumo médio de FDN igual a $0,91 \%$ PV e concluíram que o consumo foi regulado pela ingestão de FDN.

Os teores de FDN expressos na base da MS total das rações variaram de 65,49 a 29,89 (Tabela 3). O maior consumo de FDN, 0,89\% PV, foi obtido com $75 \%$ de volumoso na ração e o menor valor encontrado, $0,45 \%$, na ração com $25 \%$ de volumoso. Estes valores estão abaixo do recomendado por SNIFFEN (1988) para vacas de leite de $1,2 \pm 0,1 \% \mathrm{PV}$. Trabalhos com gado de corte, nesse sentido, são escassos e indicam que o consumo de FDN deve estar próximo a 1,0\% PV (RESENDE et al., 1994).

CARVALHO et al. (1997a) trabalharam com teores de 68,1; 59,5; 52,7; 42,3; e 37,0\% de FDN na MS das rações de novilhos zebuínos (anelorados) e encontraram maior consumo de FDN, 0,99\% do PV, para o tratamento com maior porcentagem de volumoso (80,0\%), sendo o menor valor, $0,58 \%$ do PV observado na ração com maior nível de concentrado $(70,0 \%)$.

MERTENS (1992) sugeriu que o teor ótimo de FDN na ração não fosse fixo e variasse conforme o

Tabela 3 - Teores médio de matéria seca (MS), matéria orgânica (MO), proteína bruta (PB), extrato etéreo $(\mathrm{EE})$, carboidratos totais $(\mathrm{CHO})$, fibra em detergente neutro (FDN) e nutrientes digestíveis totais (NDT) e concentração de energia metabolizável (EM) na ração experimental

Table 3 - Dry matter (DM), organic matter (OM), crude protein (CP), ether extract (EE), total carbohydrates (CHO), neutral detergent fiber (NDF) and total digestible nutrients (TDN) average content and metabolizable energy concentration in the experimental diet

\begin{tabular}{|c|c|c|c|c|c|}
\hline \multirow[t]{2}{*}{ Item } & \multicolumn{5}{|c|}{$\begin{array}{c}\text { Ração experimental } \\
\text { Experimental diet }\end{array}$} \\
\hline & 25,0 & 37,5 & 50,0 & 62,5 & 75,0 \\
\hline $\mathrm{MS} \%$ & 88,79 & 88,46 & 88,91 & 89,76 & 89,48 \\
\hline $\begin{array}{l}D M \\
\mathrm{MO}^{1}\end{array}$ & 95,48 & 95,67 & 96,01 & 96,52 & 96,47 \\
\hline $\begin{array}{l}O M \\
\mathrm{~PB}^{1} \\
C P\end{array}$ & 11,35 & 11,17 & 11,48 & 11,62 & 12,52 \\
\hline $\mathrm{EE}^{1}$ & 1,34 & 1,69 & 2,10 & 2,30 & 2,53 \\
\hline $\mathrm{CHO}^{1}$ & 82,79 & 82,81 & 82,44 & 82,59 & 81,33 \\
\hline $\mathrm{FDN}^{1}$ & 65,49 & 56,88 & 48,15 & 39,27 & 29,89 \\
\hline $\begin{array}{l}N D F \\
\text { NDT }^{1}\end{array}$ & 55,87 & 59,55 & 67,17 & 66,97 & 76,40 \\
\hline $\begin{array}{l}T D N \\
\mathrm{EM}^{2} \\
M E\end{array}$ & 2,02 & 2,15 & 2,43 & 2,42 & 2,76 \\
\hline
\end{tabular}

\footnotetext{
1 Porcentagem da MS.

$2 \mathrm{kcal} / \mathrm{g}$ MS.

1 Percentage of DM.

$2 \mathrm{kcal} / \mathrm{g} D \mathrm{M}$.
} 
CARDOSO et al.

Tabela 4 - Média, regressão e coeficientes de determinação $\left(\mathrm{r}^{2}\right)$ e variação (CV\%), para os consumos de matéria seca (MS), matéria orgânica (MO), proteína bruta (PB), extrato etéreo (EE), carboidratos totais $(\mathrm{CHO})$, fibra em detergente neutro (FDN) e nutrientes digestíveis totais (NDT), em função dos níveis de concentrado na ração

Table 4 - Mean, regression and coefficients of determination $\left(r^{2}\right)$ and variation (CV\%), for the dry matter (DM), organic matter (OM), crude protein (CP), ether extract $(E E)$, total carbohydrates $(C H O)$, neutral detergent fiber (NDF) and total digestible nutrients (TDN) intakes, on the dietary levels of concentrate

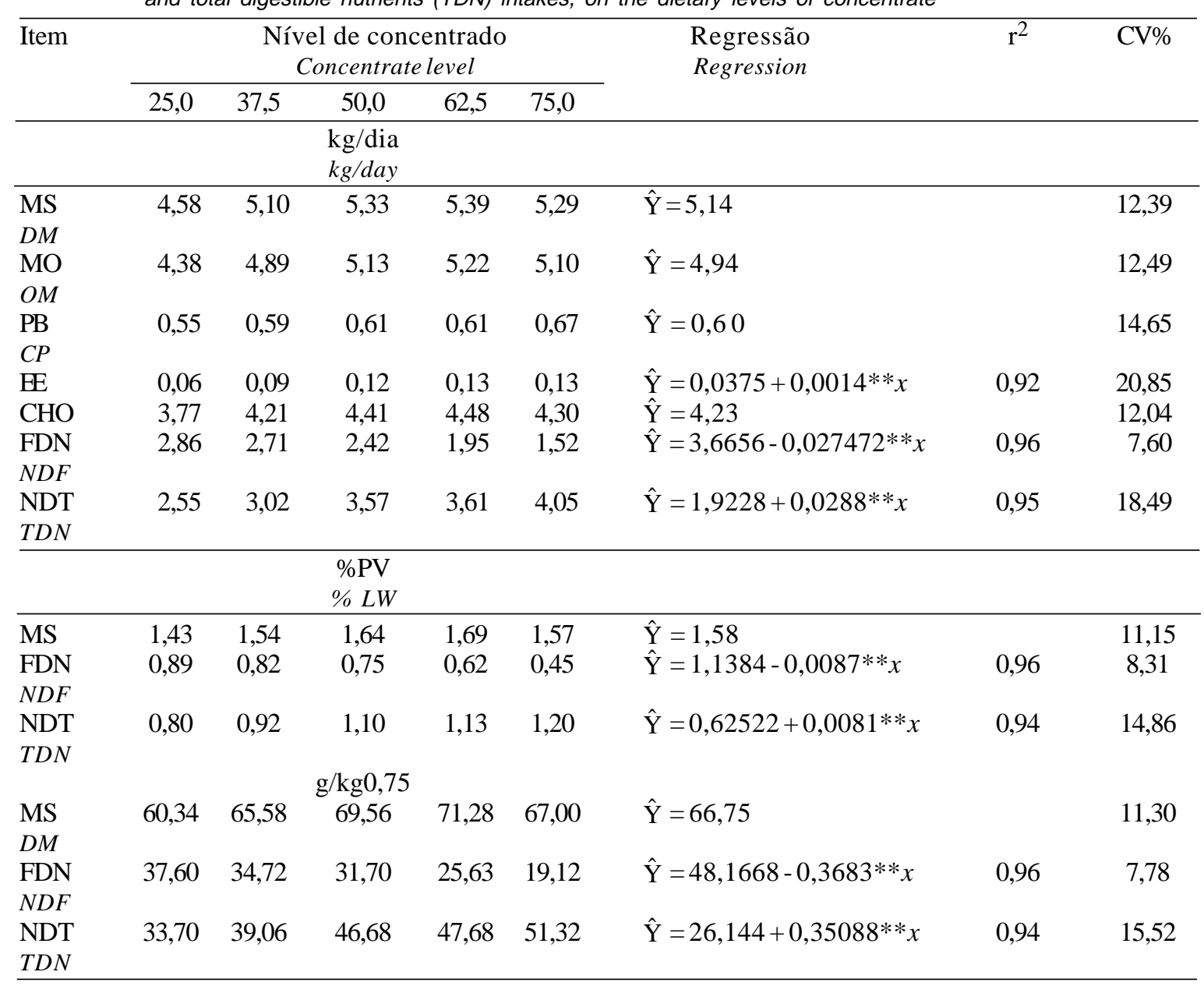

** Significativo a $1 \%$ de probabilidade, pelo teste t.

** Significant at $1 \%$ of probability by $t$ test.

requerimento de energia líquida do animal. Observa-se que, quando o volume da ração é o fator limitante de consumo, os animais necessitam de maior ingestão de nutrientes para suprir a demanda fisiológica; contrariamente, ao se adicionar concentrado, obtém-se aumento da ingestão de energia até determinado ponto - ponto de transição entre o controle físico e fisiológico - e, em seguida, o consumo estabiliza-se. Nesse caso, o animal ingere energia suficiente para atender sua demanda fisiológica.

VAN SOEST e MERTENS (1984) afirmaram que o conteúdo de fibra na ração reduziu o consumo voluntário, devido ao "enchimento" do rúmen, quando as rações continham alto teor de FDN. Esse efeito depressor do conteúdo de fibra é mais evidente quando as rações suprem de uma a três vezes os requerimentos de mantença do animal. Rações com alto teor de concentrado (acima de $75 \%$ na MS), baixo teor de fibra (abaixo de $25 \%$ ) e digestibilidade elevada (acima de $66 \%$ ) podem resultar em menor consumo MS, uma vez que as necessidades energéticas são atendidas em menores níveis de consumo (MERTENS, 1992, VAN SOEST, 1994).

MERTENS (1994) afirmou que a ingestão seria limitada pelo efeito físico de "enchimento", quando o consumo de FDN fosse de 11 a 13 g/kg PV. Nesse experimento, o consumo de FDN foi 8, 9; 8, 2; 7,5; 6,2; e $4,5 \mathrm{~g} / \mathrm{kg} \mathrm{PV}$, para os animais que receberam 25,0 ; 37,$5 ; 50,0 ; 62,5 ;$ e $75,0 \%$ de concentrado, respectivamente. Pode-se sugerir que o consumo voluntário 
1838 Rev. bras. zootec.

observado neste trabalho, quando a ração continha maior proporção de feno, possivelmente foi limitado pelo "enchimento" do rúmen, mas, para os demais tratamentos, com maior proporção de concentrado, o limite foi a demanda fisiológica de energia para o animal.

Observou-se que não houve efeito dos níveis de concentrado sobre o consumo de $\mathrm{PB}(\mathrm{P}>0,05)$, média $0,60 \mathrm{~kg} / \mathrm{dia}$, uma vez que as rações continham aproximadamente $12 \%$ de PB e não houve variação na ingestão de MS entre os tratamentos. CARVALHO et al. (1997a) trabalharam com níveis de 20,0; 32,5; 45,0; 57,5; e 70,0\% de concentrado, mantendo-se a quantidade de $\mathrm{PB}$ da ração, e encontraram valor médio para o consumo de PB de 0,46 kg/dia.

Resultados similares foram observados para o consumo de carboidratos totais (CHO), média de $4,23 \mathrm{~kg} / \mathrm{dia}$ para os cinco níveis de concentrado $(\mathrm{P}>0,05)$, uma vez que volumosos e concentrados apresentaram concentrações similares deste nutriente na MS (Tabela 3) e não houve efeito no consumo de MS.

Os resultados de aumentos lineares no consumo de $\mathrm{EE}(\mathrm{P}<0,01)$, expresso em kg/dia, concordam com os encontrados por CARVALHO et al. (1997a), LADEIRA (1998) e DIAS (1999). Esses autores atribuíram o resultado à maior concentração desse nutriente nas rações experimentais, à medida que se elevaram os níveis de concentrado. Pela análise da Tabela 2, o feno com $0,95 \%$ de EE foi substituído por níveis crescentes de concentrado, fazendo com que o teor de EE na MS da ração se elevasse de 1,34; 1,69; 2,10; 2,30; e 2,53 nos respectivos níveis de concentrado desta pesquisa (Tabela 3 ).

Os consumos de NDT, em kg/dia, \%PV e g/ $/ \mathrm{kg}^{0,75}$, aumentaram linearmente $(\mathrm{P}<0,01)$, ao se adicionar concentrado nas rações, em função da melhor digestibilidade de PB, EE e CHO e, também, do maior consumo de EE.

Os coeficientes de digestibilidades aparentes totais da MS e MO, as equações de regressão e os coeficientes de variação e determinação encontram-se na Tabela 5 .

Foi observado comportamento linear crescente $(\mathrm{P}<0,01)$ para os coeficientes de digestibilidade aparentes total da MS e MO, ao se elevarem os níveis de concentrado na ração. A digestibilidade aparente da MS variou de 54,90 a 75,23\%, sendo semelhante ao efeito linear crescente relatado por BERCHIELLI (1994), CASSIDA et al. (1994) e DIAS (1999). O comportamento linear crescente da digestibilidade da MS foi atribuído à maior concentração de carboidratos totais digestíveis em relação aos carboidratos estruturais, presentes nas rações com maiores proporções de concentrados.

HUSSEIN et al. (1995) e DUTRA et al. (1997) obtiveram maiores coeficientes de digestibilidade da MO, para as rações com menor porcentagem de volumosos, dando suporte aos resultados encontrados neste trabalho. Entretanto, CARVALHO et al. (1997a) verificaram comportamento quadrático para as digestibilidade aparentes de MS e MO, em que os valores máximos foram estimados em 59,8 e 61,7\%, com 42,0 e 40,5\% de concentrado nas rações, respectivamente. LADEIRA (1998) encontrou digestibilidade aparente mínima para MS e MO em 67,27 e $68,31 \%$, com 36,71 e $41,50 \%$ de concentrado, respectivamente.

Não houve efeito dos níveis de concentrado nas rações $(\mathrm{P}>0,05)$ sobre as digestões de MS e MO no rúmen, intestinal total, intestino delgado (ID) e intestino grosso (IG), que foram, em média, 54,45 e 64,67; 45,55 e 35,$34 ; 42,84$ e 34,43 ; e 7,33 e 0,16 , respectivamente. TIBO et al. (1997), BÜRGER et al. (1998), LADEIRA (1998) e DIAS (1999) também não observaram variação no coeficiente de digestibilidade ruminal da MS, obtendo-se valores médios de 50,48; 48,52; 63,35; e 57,48\%, respectivamente.

CARVALHO et al. (1997b) encontraram valor médio de $62,61 \%$ para a digestibilidade ruminal de MS; a digestibilidade da MO comportou-se de forma quadrática. A estimativa de digestão máxima foi de $80,28 \%$ para o nível de $40,5 \%$ de concentrado. VALADARES FILHO et al. (1990) e LADEIRA (1998) verificaram valores constantes para a digestibilidade ruminal da MO de 72,5 e 71,42\%, respectivamente. Todavia, ANDRADE (1992), TIBO et al. (1997) e DIAS (1999) encontraram reduções lineares para o coeficiente de digestibilidade ruminal da MO, ao se elevar o nível de concentrado na ração. Este comportamento pode ser atribuído à redução nos valores de $\mathrm{pH}$ ruminal, que possivelmente prejudicaria a digestão da fibra.

No presente experimento, não foi observado efeito dos níveis de concentrado sobre as digestibilidades intestinais total da MS e MO ( $\mathrm{P}>0,05)$, sendo obtidos valores de 45,55 e 35,34, respectivamente. DIAS (1999) não observou efeito dos níveis de concentrado na digestibilidade intestinal da MS, que foi $42,52 \%$. Entretanto, em relação à digestibilidade intestinal da MO, o autor observou efeito linear positivo.

Os valores médios encontrados para as digestibilidades aparentes da MS e MO no intestino 
CARDOSO et al.

Tabela 5 - Média, regressão e coeficientes de determinação $\left(\mathrm{r}^{2}\right)$ e variação $(C V \%)$, para as digestibilidades ( $\hat{Y}$, em \%) aparentes total, ruminal e intestinal total, nos intestinos delgado e grosso, da matéria seca (MS) e matéria orgânica (MO), em função dos níveis de concentrado na ração

Table 5 - Mean, regression and coefficients of determination $\left(r^{2}\right)$ and variation (CV\%), for the total, ruminal and total intestinal apparent digestibilities, in the small and large intestines, of dry matter (DM) and organic matter $(O M)$, on the dietary levels of concentrate

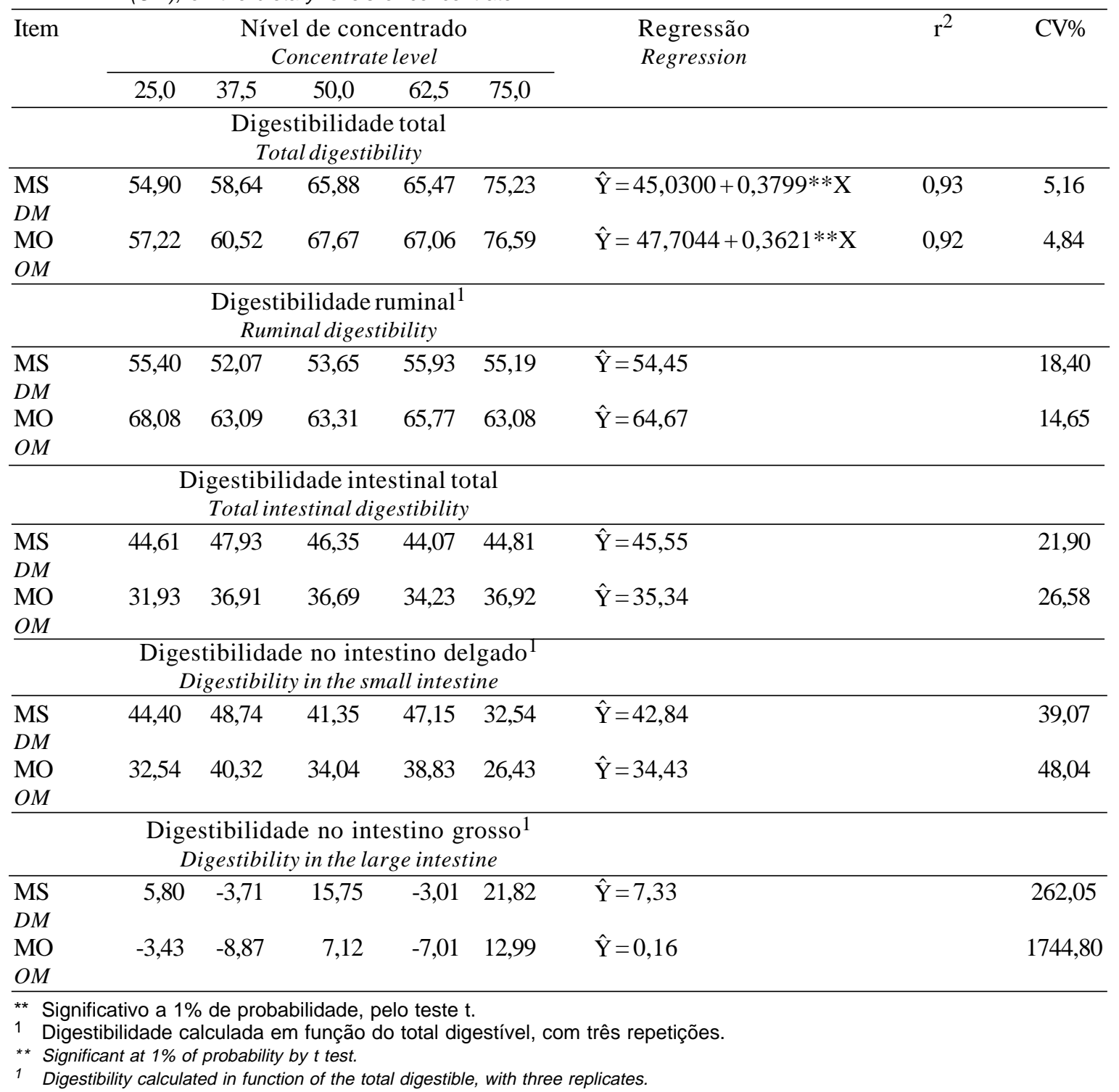

delgado foram de 42,84 e $34,43 \%$, respectivamente. Garcia (1982), Valadares Filho et al. (1990), Araújo (1993) e Dutra (1996), citados por CARVALHO et al. (1997b), incluindo também o último autor, não encontraram efeito do nível de concentrado na digestão da MS no ID, observando-se valor médio de $43,13 \%$.

No intestino grosso, as digestibilidades aparentes da MS, média 7,33\%, e da MO, média $0,16 \%$, não foram influenciadas pelo nível de concentrado nas rações $(\mathrm{P}>0,05)$. Estes valores estão próximos dos encontrados por CARVALHO et al. (1997b), para a digestibilidade no IG da MS e MO (5,50 e 1,38\%, respectivamente).
DIAS (1999), trabalhando com níveis semelhantes de concentrado na ração de novilhos F1 Limousin $\mathrm{x}$ Nelore, encontrou efeito quadrático para as digestibilidades aparentes da MS e MO nos intestinos delgado e grosso. No ID, as digestões máximas de MS, $42,45 \%$, foram estimadas com $55,16 \%$ de concentrado na ração e para MO, 35,37\%, com 58,14\% de concentrado. No IG, as digestibilidades mínimas para MS e MO, 1,21 e -1,18\%, foram estimadas com 54,12 e $52,60 \%$ de concentrado, respectivamente. Contudo, LADEIRA (1998) verificou comportamento linear crescente para digestibilidades aparentes da MS e MO no ID e linear decrescente para as 
1840 Rev. bras. zootec.

Tabela 6 - Média, regressão e coeficientes de determinação $\left(r^{2}\right)$ e variação $(C V \%)$, para as digestibilidades aparentes total, ruminal e intestinal total, nos intestinos delgado e grosso, de proteína bruta (PB) e extrato etéreo (EE), e para a digestibilidade aparente no intestino delgado dos compostos nãoamoniacais (NNA), em função dos níveis de concentrado na ração (X)

Table 6 - Mean, regression and coefficients of determination $\left(r^{2}\right)$ and variation (CV\%), for the total, ruminal and total intestinal apparent digestibilities, in the small and large intestines, of crude protein (CP) and ether extract (EE), and for the apparent digestibility of the non ammonia compounds, in the small intestine, on the dietary levels of concentrate $(X)$

\begin{tabular}{|c|c|c|c|c|c|c|c|c|}
\hline \multirow[t]{2}{*}{ Item } & \multicolumn{5}{|c|}{$\begin{array}{l}\text { Nível de concentrado } \\
\text { Concentrate level }\end{array}$} & \multirow[t]{2}{*}{$\begin{array}{l}\text { Regressão } \\
\text { Regression }\end{array}$} & \multirow[t]{2}{*}{$\mathrm{r}^{2}$} & \multirow[t]{2}{*}{$\mathrm{CV} \%$} \\
\hline & 25,0 & 37,5 & 50,0 & 62,5 & 75,0 & & & \\
\hline \multicolumn{9}{|c|}{$\begin{array}{l}\text { Digestibilidade total } \\
\text { Total digestibility }\end{array}$} \\
\hline $\begin{array}{l}\mathrm{PB} \\
C P\end{array}$ & 55,95 & 52,84 & 60,64 & 57,56 & 68,73 & $\hat{\mathrm{Y}}=47,0352+0,2422 * * \mathrm{X}$ & 0,63 & 9,77 \\
\hline $\mathrm{EE}$ & 63,08 & 71,04 & 78,29 & 74,32 & 81,67 & $\hat{\mathrm{Y}}=57,4984+0,3237 * * \mathrm{X}$ & 0,80 & 7,76 \\
\hline \multicolumn{9}{|c|}{$\begin{array}{c}\text { Digestibilidade ruminal }^{1} \\
\text { Ruminal digestibility }^{2}\end{array}$} \\
\hline PB & $-10,34$ & $-19,36$ & $-12,52$ & $-9,12$ & 1,72 & $\hat{\mathrm{Y}}=-9,92$ & & 198,49 \\
\hline $\begin{array}{l}C P \\
\mathrm{EE}\end{array}$ & $-83,19$ & $-75,82$ & $-53,74$ & $-44,46$ & $-29,04$ & $\hat{\mathrm{Y}}=113,618+1,1266^{* *} \mathrm{X}$ & 0,98 & 36,15 \\
\hline \multicolumn{9}{|c|}{$\begin{array}{l}\text { Digestibilidade intestinal total } \\
\text { Total intestinal digestibility }\end{array}$} \\
\hline $\begin{array}{l}\mathrm{PB} \\
C P\end{array}$ & 59,04 & 60,48 & 64,98 & 59,29 & 67,26 & $\hat{\mathrm{Y}}=55,9458+0,1292 * \mathrm{X}$ & 0,46 & 8,78 \\
\hline $\mathrm{EE}$ & 78,65 & 83,54 & 85,84 & 82,31 & 85,69 & $\hat{Y}=78,4218+0,0992 * X$ & 0,46 & 5,05 \\
\hline \multicolumn{9}{|c|}{$\begin{array}{c}\text { Digestibilidade no intestino delgado } \\
\text { Digestibility in the small intestine }\end{array}$} \\
\hline $\begin{array}{l}\mathrm{PB} \\
C P\end{array}$ & 64,00 & 69,89 & 65,70 & 62,54 & 61,31 & $\hat{\mathrm{Y}}=64,69$ & & 11,62 \\
\hline $\mathrm{EE}$ & 86,85 & 88,02 & 89,06 & 85,71 & 58,22 & $\hat{Y}=81,57$ & & 30,49 \\
\hline NNA & 72,54 & 89,64 & 88,07 & 87,51 & 64,10 & $\hat{\mathrm{Y}}=80,43$ & & 22,94 \\
\hline \multicolumn{9}{|c|}{$\begin{array}{c}\text { Digestibilidade no intestino grosso } \\
\text { Digestibility in the large intestine }\end{array}$} \\
\hline $\begin{array}{l}\mathrm{PB} \\
\mathrm{CP}\end{array}$ & $-13,86$ & $-21,03$ & $-9,65$ & $-14,32$ & $-8,48$ & $\hat{\mathrm{Y}}=13,47$ & & 107,73 \\
\hline $\mathrm{EE}$ & $-38,55$ & $-58,15$ & $-25,82$ & $-18,78$ & $-13,08$ & $\hat{\mathrm{Y}}=30,88$ & & 189,34 \\
\hline
\end{tabular}

digestibilidades aparentes desses nutrientes no IG, atribuindo os resultados à maior quantidade de carboidratos estruturais nas rações com menores níveis de concentrado.

Nas digestibilidades aparentes totais de PB e EE, foram observados aumentos lineares $(\mathrm{P}<0,01)$ com o aumento dos níveis de concentrado nas rações (Tabela 6). DIAS (1999) encontrou resultados semelhantes para teores de PB e EE, atribuindo-os à menor proporção da fração endógena e ao aumento no consumo desses nutrientes. Nesse caso, o consumo de PB tendeu ser maior, quando a quantidade de concentrado da ração se elevou, mesmo não sendo observado efeito dos níveis de concentrado.
Os dados obtidos diferem de alguns autores que não observaram influência dos níveis de concentrado sobre as digestibilidades aparentes totais de PB e EE (CARVALHO et al., 1997a) e a digestibilidade aparente total da PB (ANDRADE, 1992, RODRIGUEZ, 1994).

O coeficiente de digestibilidade de $\mathrm{PB}$ no rúmen foi, em média, negativo, $9,92 \%$. Os valores negativos para os tratamentos com 25,$0 ; 37,5 ; 50,0$; e $62,5 \%$ de concentrado indicam maior captação de amônia de fontes endógenas.

LADEIRA (1998) não trabalhou com rações isoprotéicas e encontrou efeito linear para a digestibilidade ruminal da PB. Concluiu que, ao se elevarem os níveis de proteína na ração, principal- 
CARDOSO et al.

Tabela 7 - Média, regressão e coeficientes de determinação $\left(\mathrm{r}^{2}\right)$ e variação (CV\%), para as digestibilidades aparentes total, ruminal, intestinal total, nos intestinos delgado e grosso, de carboidratos totais $(\mathrm{CHO})$ e fibra em detergente neutro (FDN), em função dos níveis de concentrado na ração

Table 7 - Mean, regression and coefficients of determination $\left(r^{2}\right)$ and variation (CV\%), for the total, ruminal and total intestinal apparent digestibilities, in the small intestine and in the large intestine, of total carbohydrates (CHO) and neutral detergent fiber (NDF), on the dietary levels of concentrate

\begin{tabular}{|c|c|c|c|c|c|c|c|c|}
\hline \multirow[t]{2}{*}{ Item } & \multicolumn{5}{|c|}{$\begin{array}{l}\text { Nível de concentrado } \\
\text { Concentratelevel }\end{array}$} & \multirow[t]{2}{*}{$\begin{array}{l}\text { Regressão } \\
\text { Regression }\end{array}$} & \multirow[t]{2}{*}{$\mathrm{r}^{2}$} & \multirow[t]{2}{*}{$\mathrm{CV} \%$} \\
\hline & 25,0 & 37,5 & 50,0 & 62,5 & 75,0 & & & \\
\hline \multicolumn{9}{|c|}{$\begin{array}{l}\text { Digestibilidade total } \\
\text { Total digestibility }\end{array}$} \\
\hline$\overline{\mathrm{CHO}}$ & 57,12 & 60,42 & 68,35 & 68,14 & 77,63 & $\hat{\mathrm{Y}}=46,8328+0,3900 * * \mathrm{X}$ & 0,93 & 4,90 \\
\hline FDN & 46,82 & 44,74 & 49,83 & 41,04 & 47,13 & $\hat{\mathrm{Y}}=45,91$ & & 12,53 \\
\hline \multicolumn{9}{|c|}{$\begin{array}{l}\text { Digestibilidade ruminal }^{1} \\
\text { Ruminal digestibility }\end{array}$} \\
\hline$\overline{\mathrm{CHO}}$ & 87,24 & 78,42 & 77,55 & 78,66 & 74,60 & $\hat{\mathrm{Y}}=79,29$ & & 12,96 \\
\hline FDN & 101,26 & 98,99 & 92,97 & 95,72 & 90,57 & $\hat{\mathrm{Y}}=95,90$ & & 14,50 \\
\hline \multicolumn{9}{|c|}{$\begin{array}{c}\text { Digestibilidade intestinal total } \\
\text { Total ruminal digestibility }\end{array}$} \\
\hline$\overline{\mathrm{CHO}}$ & 12,76 & 21,58 & 22,45 & 21,35 & 25,40 & $\hat{\mathrm{Y}}=20,71$ & & 48,67 \\
\hline FDN & $-1,26$ & 1,01 & 7,03 & 4,28 & 9,43 & $\hat{\mathrm{Y}}=4,10$ & & 320,94 \\
\hline \multicolumn{9}{|c|}{$\begin{array}{c}\text { Digestibilidade no intestino delgado } \\
\text { Digestibility in the small intestine }\end{array}$} \\
\hline$\overline{\mathrm{CHO}}$ & 6,50 & 23,30 & 18,76 & 26,25 & 14,92 & $\hat{\mathrm{Y}}=17,95$ & & 93,89 \\
\hline FDN & $-8,46$ & 16,27 & $-6,58$ & 8,60 & $-33,95$ & $\hat{\hat{Y}}=4,82$ & & 591,891 \\
\hline \multicolumn{9}{|c|}{$\begin{array}{l}\text { Digestibilidade no intestino grosso } \\
\text { Digestibility in the large intestine }\end{array}$} \\
\hline$\overline{\mathrm{CHO}}$ & $-1,44$ & $-5,89$ & 7,89 & $-5,46$ & 12,94 & $\hat{\mathrm{Y}}=1,61$ & & 615,04 \\
\hline FDN & $-3,72$ & $-13,40$ & 15,58 & $-3,67$ & 37,68 & $\hat{\mathrm{Y}}=6,49$ & & 368,38 \\
\hline
\end{tabular}

** Significativo a $1 \%$ de probabilidade, pelo teste $\mathrm{t}$

1 Digestibilidade calculada em função do total digestível, com três repetições.

** Significant at $1 \%$ of probability by $t$ test.

1 Digestibility calculated in function of the total digestible, with three replicates.

mente com fontes mais degradadas no rúmen, as perdas nitrogenadas são maiores.

Foi observado aumento linear $(\mathrm{P}<0,01)$ para a digestibilidade ruminal do EE. O mesmo efeito foi verificado por DIAS (1999); porém, CARVALHO et al. (1997b) não observaram diferença na digestibilidade ruminal do EE, com o aumento dos níveis de concentrado na ração, obtendo valor médio de $8,85 \%$. Os valores negativos encontrados para todas as rações, no que se refere aos coeficientes de digestibilidades aparente de EE no rúmen, podem ser conseqüência da síntese de lipídeos microbianos.

As digestibilidades aparentes no ID de PB e EE não foram influenciadas pelo nível de concentrado nas rações $(\mathrm{P}>0,05)$, os valores médios foram 64,69 e $81,57 \%$, respectivamente. O resultado encontrado para PB está de acordo aos observados por CARVALHO et al. (1997b). No entanto, LADEIRA (1998) e DIAS (1999) observaram aumento linear para a digestibilidade intestinal da PB no ID, com aumento no nível de concentrado da ração. Em média, $81,57 \%$ do teor de EE que chegou no ID foi digerido, valor próximo a $80,16 \%$ encontrado por CARVALHO et al. (1997b).

Observa-se que a digestibilidade intestinal dos compostos nitrogenados não-amoniacais foi, em média, 80,43\%. O AGRICULTURAL RESEARCH COUNCIL - ARC (1984) e o NRC (1985) adotaram, respectivamente, valores de 85 e $80 \%$ para a digestibilidade verdadeira destes compostos. O AGRICULTURAL AND FOOD RESEARCH COUNCIL-AFRC (1992) assumiu o valor de $90 \%$ de digestibilidade intestinal de proteína dietética - NIDA, no ID. O CORNELL NET CARBOHIDRATE AND PROTEIN SYSTEM-CNCPS considerou valores para as três frações protéicas potencialmente digestíveis: $100 \%$ para as frações $B_{1}$ e $B_{2}$ e $80 \%$ para a fração $B_{3}$ (SNIFFEN et al., 1992).

Não se observou também, no IG, efeito dos níveis de concentrados sobre os coeficientes de digestibilidade 
1842 Rev. bras. zootec.

de PB e EE ( $>>0,05)$, sendo encontrados valores médios negativos, 13,47 e $30,88 \%$, respectivamente. CARVALHO et al. (1997b) encontraram coeficiente de digestibilidade aparente de PB negativo, 10,92\%, constatando que, possivelmente, os valores negativos para a digestão de proteínas nesse compartimento são provenientes da contribuição da síntese microbiana ou secreção de nitrogênio endógeno para o IG.

Os coeficientes de digestibilidade totais e parciais de FDN e CHO estão na Tabela 7.

O nível de concentrado na ração aumentou linearmente a digestibilidade total de $\mathrm{CHO}(\mathrm{P}<0,01)$, concordando com os resultados de LADEIRA (1998) e DIAS (1999). Este fato pode ser explicado pela maior concentração de carboidratos não-estruturais, que são mais digestíveis que os estruturais, nas rações com maiores níveis de concentrados.

A digestibilidade aparente de FDN não foi influenciada pelos níveis de concentrados das rações ( $\mathrm{P}>0,05)$, sendo o valor médio de $45,91 \%$, que está próximo aos $49,1 \%$ observados por CARVALHO et al. (1997a). O consumo médio de MS de $66,75 \mathrm{~g} / \mathrm{kg}^{0,75}$ pode explicar parcialmente a ausência de efeito de maiores níveis de concentrado sobre o coeficiente de digestibilidade aparente da FDN, ou seja, o pH ruminal manteve-se dentro de limites fisiológicos, em todos os níveis de concentrados, e não houve redução no número de bactérias celulolíticas, principais responsáveis pela digestão da fibra.

Não foram encontradas diferenças para as digestibilidades ruminais de $\mathrm{CHO}(79,29 \%)$ e FDN $(95,90 \%)$, ao se elevarem os níveis de concentrados das rações $(\mathrm{P}>0,05)$. Foi possível observar que $95,90 \%$ da FDN foi fermentada no rúmen, média semelhante aos 99,90\% encontrados por CARVALHO et al. (1997b). A ausência de efeito do nível de concentrado sobre a digestibilidade ruminal de carboidratos totais (CHO) também foi observada por STOKES et al. (1991), que trabalharam com rações contendo 31 ou $38 \%$ de carboidratos não-estruturais.

A digestibilidade intestinal total de $\mathrm{CHO}$ e FDN foi, em média, 20,71 e 4,10\%, respectivamente, para os cinco níveis de concentrado usados nas rações experimentais.

Os níveis de concentrados nas rações não influíram $(\mathrm{P}>0,05)$ nas digestibilidades aparentes no ID de CHO e FDN, sendo encontrados valores médios de 17,95 e -4,82, respectivamente. Comportamento semelhante foi obtido por CARVALHO et al. (1997b). $O$ valor negativo de $-4,82$ para digestibilidade da FDN no ID pode indicar pequeno erro na estimativa de fluxos de MS, já que não há digestão de FDN neste compartimento.

No intestino grosso, não foram observadas variações nas digestões de $\mathrm{CHO}$ e FDN, que apresentaram valores médios de 1,61 e 6,49\%, respectivamente.

\section{Conclusões}

O consumo de MS, MO, PB e CHO não se alterou, o de EE e NDT aumentou e o de FDN diminuiu linearmente, ao se elevarem os níveis de concentrados nas rações.

As digestibilidades aparentes totais de MS, MO, $\mathrm{PB}, \mathrm{EE}$ e CHO tiveram comportamento linear positivo, em função de níveis crescentes de concentrados nas rações experimentais.

Os níveis de concentrados não alteraram as digestibilidades ruminais e intestinais da MS e MO, que foram, em média, 54,45 e 45,55 e 64,67 e 35,34, respectivamente.

O aumento do nível de concentrado nas rações não alterou o local de digestão dos nutrientes.

\section{Referências Bibliográficas}

AGRICULTURAL AND FOOD RESEARCH COUNCIL AFRC. 1991. Technical committee on response to nutrients, Report 8. Voluntary intake of cattle. Nutrition Abstracts and Reviews, 61(9):815-823.

AGRICULTURAL RESEARCH COUNCIL - ARC. 1984. Report of the protein group of the Agricultural Research Council Working Party, on the nutrient requirement of ruminants. London: Commonwealth Agricultural Bureaux. 45p.

ANDRADE, A.T. Digestão total e parcial da matéria seca, matéria orgânica, energia bruta e proteína bruta em diferentes grupos genéticos de bovídeos. Viçosa, MG: UFV, 1992. 181p. Tese (Doutorado em Zootecnia) - Universidade Federal de Viçosa, 1992.

BERCHIELLI, T.T. Efeito da relação volumoso para concentrado sobre a partição da digestão, síntese de proteína microbiana, produção de ácidos graxos voláteis e o desempenho de novilhos em confinamento. Belo Horizonte, MG; UFMG - 1994. 104 p. Tese (Doutorado em Zootecnia) Universidade Federal de Minas Gerais, 1994.

BÜRGER, P.J., PEREIRA, J.C., COELHO DA SILVA, J.F. et al. Consumo e digestibilidade em bezerros alimentados com dietas contendo diferentes níveis de concentrado. In: REUNIÃO ANUAL DA SOCIEDADE BRASILEIRA DE ZOOTECNIA, 35. 1988, Botucatu. Anais... Botucatu: SBZ, 1998, p.599-601.

CARVALHO, A.U., VALADARES FILHO, S.C., COELHO da SILVA, J.F. et al. 1997a. Níveis de concentrados em dietas de zebuínos. 1. Consumo e digestibilidade aparente. R. Bras. Zootec., 26(5):986-995.

CARVALHO, A.U., VALADARES FILHO, S.C., COELHO DA SILVA, J.F. et al. 1997b. Níveis de concentrados em dietas de zebuínos. 2. Coeficientes e digestibilidades aparentes parciais. R. Bras. Zootec., 26(5):996-1006.

CASSIDA, K.A., BARTON, B.A., HOUGH, R.L. et al. 1994 
Feed intake and apparent digestibility of hay-supplemented brassica diets for lambs. J. Anim. Sci., 72(6):1623-1629.

DIAS, H.L.C. Consumo, digestibilidades aparentes totais e parciais de dietas contendo diferentes níveis de concentrado, em novilhos F1 Limousin x Nelore. Viçosa, MG: UFV, 1999. 76p. Dissertação (Mestrado em Zootecnia) - Universidade Federal de Viçosa, 1999.

DOVE, H. 1996. The ruminant, the rumen and the pasture resource: nutrient interactions in the grazing animal. In: HODGSON, J., ILLUS, A.W. (Eds.) The ecology and management of grazing systems (eds.) CAB INTERNACIONAL. p.219-246.

DUTRA, A.R., QUEIROZ, A.C., PEREIRA, J.C. et al. 1997. Efeito dos níveis de fibra e das fontes de proteínas sobre o consumo e digestão dos nutrientes em novilhos. R. Bras. Zootec., 26(4):787-796.

GESUALDI, JR., A. Níveis de concentrado na dieta de novilhos F1 Limousin x Nelore, em confinamento: desempenho produtivo e características de carcaça. Viçosa, MG: UFV, 1999. 82p. Dissertação (Mestrado em Zootecnia) - Universidade Federal de Viçosa, 1999.

HUSSEIN, H.S., MERCHEN, N.R., FAHEY JR., G.C. 1995. Effects of forage level and canola seed supplementation on site and extent of digestion of organic matter, carbohydrates, and energy by steers. J. Anim. Sci., 73(8):2458-2468.

LADEIRA, M.M. Consumo e digestibilidades aparentes totais e parciais de dietas contendo diferentes níveis de concentrado, em novilhos nelore. Viçosa, MG: UFV, 1998. 71p. Dissertação (Mestrado em Zootecnia) - Universidade Federal de Viçosa, 1998.

LEÃO, M.I., COELHO DA SILVA, J.F. Técnica de fistulação de abomaso em bezerros. In: CONGRESSO BRASILEIRO DE ZOOTECNIA, 1. REUNIÃO ANUAL DA SOCIEDADE BRASILEIRA DE ZOOTECNIA, 17, 1980, Fortaleza. Anais... Fortaleza: SBZ, 1980, p.37.

MERTENS, D.R. Analysis of fiber and its use in feed evaluation and ration formulation. In: SIMPÓSIO INTERNACIONAL DE RUMINANTES, 1992. Lavras. Anais... Lavras: SBZ, 1992, p.1-32.

MERTENS, D.R. Balancing carbohydrates in dairy rations. In: LARGE HERD DAIRY MANAGEMENT CONFERENCE DEPARTMENT OF ANIMAL SCIENCE, Cornell, 1988, Ithaca. Proceedings... Ithaca: Cornell University, p.150161, 1988.

MERTENS, D.R. 1994. Regulation of forage intake. In: FAHEY JR., G.C. (Ed.). Forage quality, evaluation and utilization. Madison: American Society of Agronomy. p.450-493.

NATIONAL RESEARCH COUNCIL - NRC. 1984. Nutrient requirements of beef cattle. 6.ed. National Academy Press: Washington, D. C. 90p.

NATIONAL RESEARCH COUNCIL - NRC. 1985. Ruminant nitrogen usage. Washington, D.C. 138p.

NATIONAL RESEARCH COUNCIL - NRC. 1996. Nutrient requirements of beef cattle. 7.ed. National Academy Press: Washington, D.C. 242p.

PATERSON, J.A., BELYEA, R.L., BOWMAN, J.P. et al. 1994. The impact of forage quality and supplementation regime on ruminant animal intake and performance. In: FAHEY JR., G.C. (Ed.). Forage quality, evaluation and utilization. Madison: American Society of Agronomy. p.59-114.

RESENDE, F.D., QUEIROZ, A.C., FONTES, C.A.A. et al.
1994. Rações com diferentes níveis de fibra em detergente neutro na alimentação de bovídeos em confinamento. R. Bras. Zootec., 23(3):366-376.

RODRIGUEZ, L.R.R. Consumo alimentar, digestibilidade, balanço de nitrogênio e excreção de minerais em bovinos (taurinos, zebuínos e bubalinos). Viçosa, MG: UFV, 1994. 69p. Dissertação (Mestrado em Zootecnia) - Universidade Federal de Viçosa, 1994.

SILVA, D.J. 1990. Análise de alimentos (Métodos químicos e biológicos). Viçosa: UFV, Impr. Univ. 165p.

SNIFFEN, C.J., BEVERLY, R.W., MOONEY, C.S. et al. 1993. Nutrient requirement versus supply in dairy cow: Strategies to account for variability. J. Dairy Sci., 76(10):3160-3178.

SNIFFEN, C.J. Balancing rations for carbohydrates for dairy cattle. In: SYMPOSIUM THE APLICATION OF NUTRITION IN DAIRY PRACTICE, 1988, Wayne, Proceedings... Wayne: American Cyanamid Company Agricultural Division, 1988. p.25-35.

SNIFFEN, C.J., O'CONNOR, C.D., VAN SOEST, P.J. et al. 1992. A net carbohydrate and protein system for evaluating cattle diets. II. Carbohydrate and protein availability. J. Anim. Sci., 70(11):3562-3577.

STOKES, S.R., HOOVER, W.H., MILLER, T.K. et al. 1991. Ruminal digestion and microbial utilization of diets varying in type of carbohydrate and protein. J. Dairy Sci., 74(3):871-881.

TIBO, G.C., VALADARES FILHO, S.C., COELHO DA SILVA, J.F. et al. Consumo, digestibilidades e metodologias de coleta de amostras de digesta em novilhos alimentados com vários níveis de concentrado. In: REUNIÃO ANUAL DA SOCIEDADE BRASILEIRA DE ZOOTECNIA, 34, 1997, Juiz de Fora. Anais... Juiz de Fora: SBZ, 1997. p.137-139.

UNIVERSIDADE FEDERAL DE VIÇOSA - UFV. 1995. SAEG - Sistema de análises estatísticas e genética. Versão 5.0. Viçosa, MG. (Manual do usuário).

VALADARES FILHO, S.C., COELHO DA SILVA, J.F., LEÃO, M.I. et al. 1990. Digestão total e parcial da matéria seca, matéria orgânica e carboidratos em novilhos holandeses, nelores e búfalos mestiços. R. Bras. Zootec., 19(5):416-423.

VAN SOEST, P.J. 1994. Nutritional ecology of the ruminants. 2.ed. Ithaca: Cornell University. 476p.

VAN SOEST, P.J., MERTENS, D.R. The use of neutral detergent fiber versus acid detergent fiber in balancing dairy rations. In: TECHINICAL SYMPOSIUM, 1984, Fresmo. Proceedings... Fresmo: Monsanto - Nutrition Chemicals Division, 1984. p.75-92.

ZINN, R.A., PLASCENCIA, A., BARAJAS, R. 1994. Interaction of forage level and monensin in diets for feedlot cattle on growth performance and digestive function. J. Anim. Sci., 72(9):2209-2215.

Recebido em: 13/07/99

Aceito em: 05/07/00 